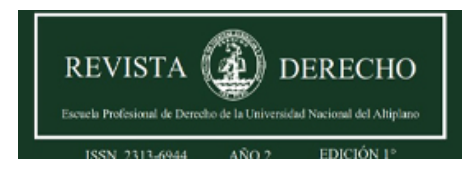

Revista de Derecho

ISSN: 2313-6944

ISSN: 2707-9651

revistaderecho@unap.edu.pe

Universidad Nacional del Altiplano

Perú

\title{
DETERMINACIÓN DEL IMPUESTO A LA RENTA SOBRE BASE PRESUNTA Y VULNERACIÓN DEL PRINCIPIO DE LEGALIDAD
}

Vilca Apaza, Henry Mark

DETERMINACIÓN DEL IMPUESTO A LA RENTA SOBRE BASE PRESUNTA Y VULNERACIÓN DEL PRINCIPIO DE LEGALIDAD

Revista de Derecho, vol. 6, núm. 2, 2021

Universidad Nacional del Altiplano, Perú

Disponible en: https://www.redalyc.org/articulo.oa?id=671870938002

DOI: https://doi.org/10.47712/rd.2021.v6i2.135

\section{(c) (7)}

Esta obra está bajo una Licencia Creative Commons Atribución 4.0 Internacional. 


\section{DETERMINACIÓN DEL IMPUESTO A LA RENTA SOBRE BASE PRESUNTA Y VULNERACIÓN DEL PRINCIPIO DE LEGALIDAD}

\section{DETERMINATION OF INCOME TAX ON ALLEGED BASIS AND VIOLATION OF THE PRINCIPLE OF LEGALITY}

Henry Mark Vilca Apaza

UNIVERSIDAD NACIONAL DEL ALTIPLANO DE

PUNO, Perú

https://orcid.org//0000-0001-6982-7645

\author{
DOI: https://doi.org/10.47712/rd.2021.v6i2.135 \\ Redalyc: https://www.redalyc.org/articulo.oa? \\ $\mathrm{id}=671870938002$
}

Recepción: 16 Junio 2021

Aprobación: 24 Junio 2021

Publicación: 04 Agosto 2022

\section{Resumen:}

El artículo tiene por objetivo analizar el método de Determinación del impuesto a la renta sobre base presunta, como potestad de la Administración tributaria en el Perú, y si su aplicación vulnera el principio de legalidad. En la praxis administrativa, es recurrente observar casos donde la administración hace uso arbitrario de este método en desmedro del patrimonio de los contribuyentes. El método de investigación empleado fue el hermenéutico y la técnica, el análisis documental, revisándose actos de la administración tributaria y jurisprudencia expedida por el Tribunal Fiscal sobre la materia. La conclusión del presente es que la Administración Tributaria, pese a tener establecidas las reglas para imponer el impuesto a la renta por el método de determinación sobre base presunta, incumple normas adjetivas vulnerando, de ese modo, el principio de legalidad prescrita en el artículo $74^{\circ}$ de la Constitución Política del Perú, ratificada en Código Tributario.

Palabras Clave: Base presunta, Determinación de obligación tributaria, Impuesto a la Renta, Principio de legalidad.

\section{Abstract:}

The article aims to analyze the method of Determination of income tax on presumed basis, as a power of the tax administration in Peru, and if its application violates the principle of legality. In administrative practice, it is recurrent to observe cases where the administration makes arbitrary use of this method to the detriment of the taxpayers' assets. The research method used was hermeneutic and technical, documentary analysis, reviewing acts of the tax administration and jurisprudence issued by the Tax Court on the matter. The conclusion of the present is that the Tax Administration, despite having established the rules to impose income tax by the method of determination on presumed basis, does not comply with adjective rules, thereby violating the principle of legality prescribed in article $74^{\circ}$ of the Political Constitution of Peru, ratified in the Tax Code.

KEYWORDS: Presumed base, Determination of tax liability, Income Tax, Principle of legality.

\section{INTRODUCCIÓN}

Es cierto que, el Estado, para atender las necesidades públicas y la agenda social, debe recaudar tributos, siendo uno de ellos, el Impuesto a la Renta, que grava directamente la ganancia del contribuyente (Alarcón, 2015). La aplicación del mismo, debe ser objetiva y legal, en el marco de los principios y normas del derecho en general y del derecho tributario en particular. Debe ser llevada a cabo con razonabilidad y bajo un marco normativo que otorgue certeza y seguridad jurídica al contribuyente (Chau y Lozano, 2000).

No existe mayor discusión, cuando el Impuesto a la Renta es determinada sobre base cierta, es decir cuando el contribuyente cuenta con toda la documentación necesaria (libro de inventarios y balances, registros de compras y ventas, entre otros) de manera que la Administración puede fijar directa y objetivamente la obligación tributaria. Pero, ¿qué sucede cuando el contribuyente no cuenta con dicha documentación, por negligencia contable o simplemente por haberlos extraviado? En este caso, la Administración Tributaria tiene 
la facultad de determinar la obligación tributaria por el método de base presunta, que justamente viene a análisis.

La Administración Tributaria, en los casos de aplicación de la facultad de determinación de la deuda tributaria sobre base presunta, ha generado recurrente discusión en los contribuyentes, en los correspondientes procedimientos contenciosos tributarios. En la aplicación de este método, la Superintendencia Nacional de Administración Tributaria (SUNAT) comete excesos en el uso de esta facultad. Por ejemplo, el Tribunal Fiscal en su resolución $\mathrm{N}^{\circ}$ 9562-4-01, ha precisado que no es legalmente posible extrapolar el método de determinación sobre base presunta para calcular el Impuesto General a la Venta, no es extensiva.

Los problemas en su aplicación no sólo se suscitan en Perú sino también en países de América latina como Costa Rica, donde la Administración Tributaria determina la aplicación de la base presunta con fundamento en un hecho base falso (Vargas, 2016). En Perú, Alarcón (2015) ya ha advertido que las normas sobre la determinación de la obligación tributaria sobre base presunta, no reflejan necesariamente los principios tributarios de realidad económica y capacidad contributiva de los contribuyentes.

En atención a todo lo expuesto, fue objetivo del presente analizar, desde la jurisprudencia, si el método de determinación del impuesto a la renta sobre base presunta aplicada por la Administración Tributaría respeta uno de los principios base del ordenamiento jurídico, constitucional y tributario, como es el principio de legalidad.

\section{FISCALIZACIÓN Y DETERMINACIÓN DE OBLIGACIÓN TRIBUTARIA}

A la administración tributaria le asiste facultades que están previstas y desarrolladas en el Capítulo II del Código Tributario (Decreto Supremo N $133-2013-E F)$, entre ellas la: Fiscalización y determinación. La fiscalización es una facultad de la Administración Tributaria prescrita en el Código Tributario que, de acuerdo al Título Preliminar de la norma, es discrecional. La discrecionalidad se entiende como "la facultad de opción entre diversas conductas posibles tanto fáctica como jurídica siempre que no implique desviación o abuso de poder" (Villegas, 1994, p. 332). Esta potestad incluye la de inspección, investigación y control del cumplimiento de la obligación tributaria, es decir, la verificación de la documentación del deudor, con la finalidad de velar por el estricto cumplimiento tanto de la obligación tributaria sustantiva como adjetiva (Baldeón, Roque y Garayar, 2009).

Por su parte, la determinación tributaria es entendida como el acto que emana de la Administración a fin de efectuar la configuración del presupuesto de hecho, la medida de lo imponible y la cuantía de la obligación (Giuliani, 2004). También puede ser conceptuada como el conjunto de actos dirigidos a determinar si existe o no la obligación tributaria; así como, quién es el obligado y cuál es la cuantía de la deuda (Villegas, 1999). Téngase presente que el este método de determinación puede ser empleada por el administrado, cuando se trata de tributos autoliquidables, o por la Administración, en casos de tributos liquidables por esta (Chau y Lozano, 2000). Cuando son lo primero, el deudor tributario lo hace mediante declaración jurada, y cuando lo efectúa la Administración, en pleno uso de su facultad fiscalizadora, obtiene la información necesaria y establece la existencia de la obligación tributaria a cargo de una empresa o persona y la respectiva cuantía.

Formas de Determinación tributaria

El artículo $63^{\circ}$ del Código Tributario (D.S. N 133-2013-EF) precisa que la determinación de la obligación tributaria es llevada a cabo por la Administración sobre base cierta y sobre base presunta. La determinación sobre Base cierta o método por estimación directa, es aquella efectuada "tomando en cuenta los elementos existentes que permitan conocer en forma directa el hecho generador de la obligación tributaria y la cuantía de la misma" (Art. 63 - Código Tributario). El método sobre base cierta es aplicable cuando el obligado cuenta con la documentación necesaria y fehaciente, esto es, con documentos (comprobantes de pago, libros y registros contables, entre otros) que permitan a la SUNAT conocer en forma directa y cierta el hecho 
generador de la obligación tributaria (Chau y Lozano, 2000). Por este método se puede establecer de forma directa el hecho generador de la obligación tributaria y la cuantía de la misma (Baldeón, Roque y Garayar, 2009).

\section{DETERMINACIÓN TRIBUTARIA SOBRE BASE PRESUNTA}

La determinación sobre base presunta o método por estimación indirecta, es una forma subsidiaria de determinar la base imponible, ante el incumplimientos de formalidades como la falta de declaración e irregularidades contables (Vargas, 2016). Se efectúa "en mérito a los hechos y circunstancias que, por relación normal con el hecho generador de la obligación tributaria, permitan establecer la existencia y cuantía de la obligación" (Art. $63^{\circ}$ - Código Tributario). Este método es aplicable cuando no se ha podido obtener la información necesaria por acción u omisión del deudor, facultándole a la Administración tributaria, acudiendo a hechos y circunstancias, a conocer de forma directa y cierta la existencia y cuantía de la obligación (Chau y Lozano, 2000; Baldeón, Roque y Garayar, 2009).

Diferencia entre base cierta y base presunta

La diferencia entre estas dos formas de determinar la obligación tributaria radica en que la determinación sobre base cierta se conoce la realización del hecho generador de la obligación tributaria, el periodo al que corresponde y la base imponible; mientras que en la determinación sobre base presunta, estos datos son obtenidos por estimaciones efectuadas sobre hechos ciertos vinculados al nacimiento de la obligación tributaria; además para su aplicación es imprescindible la existencia de una causal debidamente acreditada conforme al artículo 64 del Código Tributario (RTF No 9826-3-2001).

El ordenamiento jurídico peruano define la presunción como el acto de razonar lógica y críticamente a partir de hechos indicadores para llegar a la certeza del hecho investigado (Artículo $277^{\circ}$ del Código Procesal Civil). La doctrina la define como un "proceso lógico conforme al cual, acreditada la existencia de un hecho -el llamado hecho base-, se concluye en la confirmación de otro que normalmente lo acompaña -el hecho presumido sobre el que se proyectan determinados efectos jurídicos" (Eseverri, 1995). Para Chau y Lozano (2000) esta operación lógico-deductiva puede ser producto de la especulación (presunción simple u hominis) o de la normalización (presunción legal), siendo esta última la adoptada en la administración tributaria. De acuerdo con la premisa anterior, la autoridad tributaria estaría impedida de actuar discrecionalmente en la apreciación de los indicios y a limitarse a su mención sin explicaciones, debiendo más bien justificar razonablemente el método aplicado para llegar a la determinación (Fonrouge, 2004), y también evidenciar que ha actuado conforme a ley. La presunción no puede ser discrecional u hominis, sino legal, y desde dicho ángulo, según Chau y Lozano (2000), las presunciones pueden ser de dos tipos: Absolutas y Relativas.

Las presunciones absolutas, conocidas también como "iuris et de iure", no admiten prueba en contrario. Siendo así, la Administración tributaria sólo debe acreditar la realidad del hecho que a ella le sirve de base. Las segundas o "iuris tantum", admiten prueba en contrario, y la carga de la prueba recae en la Administración tributaria.

\section{MÉTODO}

La investigación se realizó en el ámbito de la Superintendencia Nacional de Administración Tributaria Sede Puno, una región localizada en la sierra del sudeste del Perú, en la Meseta del Collao, limita por el sur, con la región Tacna; por el este, con el Estado Plurinacional de Bolivia; y por el Oeste, con la región Cusco, Arequipa y Moquegua. Puno, se encuentra en el altiplano a $3812 \mathrm{msnm}$, a orillas del Lago Titicaca.

El estudio corresponde al tipo descriptivo (Gómez, 2012; Hernández, 2017). El método empleado es el hermenéutico jurídico, propio del derecho, permitiendo el proceso interpretativo y analítico de la dogmática 
y jurisprudencia del ámbito tributario. La técnica empleada es el análisis documental, el mismo que ha permitido revisar sentencias del Tribunal Fiscal y la Resolución de Determinación Nº 074-003-0022523 referida a la facultad de la Administración Tributaria de determinar obligaciones tributarias sobre base presunta.

\section{DESARROLLO: RESULTADOS Y DISCUSIÓN}

\section{ANÁLISIS DE LAS EXIGENCIAS DEL TRIBUNAL FISCAL PARA DETERMINAR LA DEUDA TRIBUTARIA SOBRE BASE PRESUNTA}

Analizada esta jurisprudencia y la norma tributaria, la máxima autoridad en materia tributaria, el Tribunal Fiscal, ha establecido dos exigencias para determinar una deuda tributaria sobre base presunta, en las Resoluciones $\mathrm{N}^{\circ}$ 143-2-2000 y $\mathrm{N}^{\circ}$ 444-3-2003. La primera es el que el Código Tributario exige, el cumplimiento de uno de los supuestos previstos en el artículo $64^{\circ}$ de dicha norma; y la segunda, la aplicación de un procedimiento de presunción expresamente contemplado en la ley.

1. Supuestos para aplicar la determinación sobre base presunta

El artículo $64^{\circ}$ del TUO del Código Tributario (D. S. N N $^{\circ}$ 133-2013-EF) indica cuáles son los hechos base o supuestos bajo los cuales la Administración Tributaria debe, excepcionalmente, utilizar el método de determinación de impuesto sobre base presunta. Esta determinación es estimatoria, debiendo ser aplicada restrictivamente (Baldeón, Roque y Garayar, 2009). La observancia de cualquiera de estos supuestos, agota el cumplimiento de esta primera exigencia. Estos supuestos en los que la SUNAT puede emplear el método sobre base presunta, entre otros son: que el obligado no haya presentado sus declaraciones tributarias o que esta, y otros documentos, ofrecieran dudas sobre su veracidad o exactitud, o que habiéndolo hecho, lo haya hecho fuera del plazo.

2. Procedimiento de determinación sobre base presunta

La segunda exigencia establecida para la Administración Tributaria es el cumplimiento de un procedimiento de determinación legalmente establecido. Este procedimiento se advierte en el capítulo XII de la Ley del Impuesto a la Renta (Decreto Legislativo $\mathrm{N}^{\circ} 1488$ ) que, en sus distintos artículos, establece la forma cómo debe determinarse la cuantía o monto del tributo, y en su artículo $91^{\circ}$ faculta a la SUNAT a aplicar la determinación de la obligación tributaria, cuando se presente las siguientes presunciones:

1) Presunción de renta neta por incremento patrimonial cuyo origen no pueda ser justificado.

2) Presunción de ventas, ingresos o renta neta por aplicación de promedios, coeficientes y/o porcentajes.

Estas presunciones son aplicables a todos los supuestos prescritos del artículo $64^{\circ}$ del Código Tributario. Sin embargo, no es suficiente la aplicación del artículo $91^{\circ}$ de la Ley del Impuesto a la Renta (aprobado por D.S. $\mathrm{N}^{\circ}$ 122-94-EF, modificado por D.S. $\left.\mathrm{N}^{\circ} 134-2004-\mathrm{EF}\right)$ para satisfacer el cumplimiento de la exigencia referida al procedimiento de determinación. El artículo $93^{\circ}$ de la misma norma precisa que para determinar la obligación tributaria sobre base presunta, la SUNAT puede "determinar ventas, ingresos o renta neta aplicando promedios, coeficientes y/o porcentajes", y que para para fijar el promedio, puede, entre otros elementos como el capital invertido en la explotación, emplear el criterio de explotación de empresas similares (Art. $93^{\circ}$ - Ley del Impuesto a la Renta). Según esta misma norma, para tal efecto, la SUNAT debe emplear el siguiente procedimiento:

3. Presunción de renta neta equivalente al promedio de renta neta de empresas similares, correspondiente al ejercicio fiscalizado o, en su defecto, al ejercicio inmediato anterior.

Cuando se opte por el tercer procedimiento, la SUNAT debe tomar como muestra tres empresas que reúnan las condiciones similares, en su defecto, tomará tres empresas con la misma Clasificación Industrial Internacional Uniforme (CIIU) (Art. 93 - Ley del Impuesto a la Renta). Para satisfacer esta última 
condición, es necesario observar el Reglamento de la Ley del Impuesto a la Renta, y el inciso a) del artículo $61^{\circ}$, que precisa que debe considerarse como empresa similar a aquella que pertenezca al mismo giro principal y se equipare en tres o más de las siguientes condiciones: “i) Número de trabajadores, ii) Puntos de venta, iii) Monto de los pasivos, iv) Monto de compras, costos o gastos, v) Consumos de agua, energía eléctrica o servicio telefónico, vi) Capital invertido en la explotación, vii) Volumen de las transacciones, viii) Existencia de mercaderías o bienes, ix) Monto de los depósitos bancarios".

En el supuesto de no haber tres empresas similares que se hallen en la misma CIIU, el numeral 4) el inciso c) del artículo $61^{\circ}$ del reglamento indica que se deberá seleccionar a aquella empresa que ostente la misma ubicación geográfica en orden de prelación en el ejercicio fiscalizado (mismo distrito, provincia, departamento, región). En tanto, el numeral 5) del inciso c) indica que 'se tomará a aquellas empresas que declaren el mayor impuesto resultante'. Finalmente, el inciso d) del artículo $61^{\circ}$ del reglamento, indica que, para el caso de las presunciones prescritas en los incisos 3) y 4) del artículo $93^{\circ}$ de la Ley del Impuesto a la Renta, y una vez seleccionadas las tres empresas o personas, se procederá a promediar las rentas netas de dichas empresas correspondientes al ejercicio fiscalizado.

\section{ANÁLISIS DEL PRINCIPIO DE LEGALIDAD EN LA TRIBUTACIÓN}

El principio de legalidad "está concebido bajo un aforismo penal muy antiguo que contempla que "no hay tributo sin ley que lo establezca”, o más conocido como "nullum tributum sine lege” (Romero, Grass y García, 2013). Dicho principio "previene que sólo y únicamente en virtud de una Ley se pueden establecer tributos, modificarlos y/o alterar sus elementos o efectos" (Oelckers, 1977). Eso quiere decir que todo tributo debe estar contemplado expresamente por una ley, con el fin de generar seguridad jurídica al contribuyente" (Romero, Grass y García, 2013; Villegas, 1999). Al respecto, la Constitución Política del Perú, en el Capítulo IV del régimen tributario y presupuestal, artículo $74^{\circ}$ - Principio de Legalidad, prescribe:

Los tributos se crean, modifican o derogan, o se establece una exoneración, exclusivamente por ley o decreto legislativo en caso de delegación de facultades. (...).

No hay duda que las obligaciones tributarias se crean por ley, contrario sensu, no tienen eficacia las normas (vale decir resoluciones) que en materia tributaria se dictan en violación de lo establecido en la carta magna (artículo $74^{\circ}$ ). Los tributos son un impuesto de creación legal, es decir, no se puede determinar impuestos al margen de lo que sustantiva y adjetivamente establece la norma.

El principio de legalidad es un principio fundamental del derecho, referente tanto para la administración (Estado) como para los servidores y funcionarios. Respecto del primero, la Administración Pública se encuentra sometida a este principio, en la medida que las entidades públicas no tienen un poder ilimitado, pues tienen sometido este poder a los límites establecidos en la Constitución Política, leyes y reglamentos, tanto en el ámbito material como en el procedimiento a seguir. Es ese el espíritu del artículo IV del Título Preliminar, numeral 1.1, de la Ley del Procedimiento Administrativo General - Ley N 27444 al definir que el Principio de Legalidad es la obligación que tienen todas las autoridades administrativas de actuar con respeto a la Constitución, la ley y al derecho, dentro de las facultades que le estén atribuidas y de acuerdo con los fines para los que les fueron conferidos. Como se colige, este principio "significa en sí primacía o prevalencia de la ley, bajo el que todo ejercicio, actividad y función de un poder público y sobre todo la facultad del "Ius Puniendi" que tiene el Estado debe realizarse acorde a las leyes vigentes, y no a la voluntad individual de las personas" (Carrasco y Arrieta, 2017), en este caso, de los servidores y funcionarios. Las actuaciones de los poderes se efectivizan en el marco del imperio de la ley. "De no ser por el principio de legalidad, el ciudadano quedaría en la más completa indefensión o desamparo, ya que, a falta de la ley, reinaría la inseguridad y con ella la arbitrariedad" (Henkel, 1968, p. 546).

El principio de legalidad es uno de los tantos que forman parte de la unidad de materia y capacidad contributiva (Romero, Grass y García, 2013), y para que ello se haga objetiva, debe ser de observancia obligatoria por las partes, además de ser justas, objetivas y respetuosas de los derechos de los contribuyentes. 
Se entiende que la finalidad del principio es el de proteger la seguridad jurídica y limitar el poder impositivo del Estado, con el fin de evitar arbitrariedades de parte de la Administración tributaria.

ANÁLISIS DE LA DETERMINACIÓN DE DEUDA TRIBUTARIA SOBRE BASE PRESUNTA EN LA RESOLUCIÓN DE DETERMINACIÓN N 074-003-0022523

En el 2018, producto de la potestad fiscalizadora, la SUNAT detectó que la recurrente (contribuyente con Ubigeo 010101, región Amazonas) no cumplió con su obligación tributaria del ejercicio 2012 y, en consecuencia, ante falta de documentos sustentatorios, pese a haber sido requerido, la Administración tributaria aplicó el procedimiento de determinación de deuda tributaria sobre base presunta (en aplicación del artículo $64^{\circ}$ - Código Tributario) mediante el procedimiento de presunción de renta neta equivalente al promedio de renta neta de empresas similares (previsto en los artículos $91^{\circ}$ y $93^{\circ}$ de la Ley del Impuesto a la Renta) y emitió la Resolución de Determinación N $074-003-0022523$, objeto de análisis del presente. Frente a este acto, la recurrente mostró su disconformidad indicando que la Administración no actuó con arreglo a ley, precisando que no seleccionó empresas con características similares sino distintas (distinto Ubigeo y patrimonio).

El derecho al debido proceso es una garantía constitucional reconocida en el artículo $139^{\circ}$ de la Constitución Política del Perú, y es de observancia obligatoria, tanto en lo jurisdiccional como administrativo. En el campo administrativo, obliga a la administración el cumplimiento de los procedimientos y formalidades establecidas por ley, garantizando al administrado el cumplimiento de principios y requisitos de un proceso libre de arbitrariedades (Vargas, s.f.) y protegiéndolo de cualquier acto del Estado que pueda afectarlo, así se ha manifestado el Tribunal Constitucional en las resoluciones $\mathrm{N}^{\circ}$ 1966-2005-HC/TC y N 8495-2006-PA/TC. Con ello, las actuaciones que realice la Administración Tributaria, específicamente referidas a la determinación de tributo sobre base presunta, deben ser con arreglo irrestricto a ley. Veamos el caso de Resolución de Determinación Nº74-003-0022523. 
TABLA 1

Evaluación de exigencias para determinar deuda tributaria sobre base presunta en la Resolución de Determinación N 074-003-0022523

\begin{tabular}{|c|c|c|c|}
\hline $\begin{array}{l}\text { Exigencias } \\
\text { para } \\
\text { determinar } \\
\text { tributo }\end{array}$ & $\begin{array}{l}\text { Supuesto o Hecho observado } \\
\text { en el acto administrativo }\end{array}$ & Calificación & $\begin{array}{r}\text { Principio } \\
\text { de legalidad }\end{array}$ \\
\hline $\begin{array}{l}\text { 1. Supuesto } \\
\text { previsto en } \text { el } \\
\text { articulo } 64^{\circ} \text { del } \\
\text { Código Tributario }\end{array}$ & $\begin{array}{l}\text { "La recurrente, pese a ser } \\
\text { requerida a fin de sustentar el } \\
\text { pasivo consignado en la cuenta } 46 \\
\text { - Otras Cuentas por Pagar, no } \\
\text { adjuntó la documentación } \\
\text { vinculada a estas operaciones que } \\
\text { acredite fehacientemente el saldo } \\
\text { pendiente de pago al } 31 \text { de } \\
\text { diciembre de } 2012 \text {, dado que los } \\
\text { contratos exhibidos carecen de } \\
\text { fecha cierta y no acreditó la } \\
\text { recepción de los préstamos" }\end{array}$ & 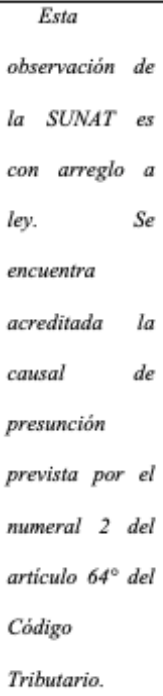 & $\begin{array}{l}\text { Cumple } \\
\text { con la } \\
\text { exigencia }\end{array}$ \\
\hline $\begin{array}{l}2 . \quad \begin{array}{r}\text { Aplicación } \\
\text { de }\end{array} \\
\text { procedimiento de } \\
\text { presunción } \\
\text { prescrito en el } \\
\text { inciso a) del } \\
\text { articulo } 61^{\circ} \text { del } \\
\text { Reglamento de la } \\
\text { Ley del Impuesto a } \\
\text { la Renta }\end{array}$ & $\begin{array}{l}\text { La SUNAT solo consideró la } \\
\text { condición referente a las ventas y } \\
\text { obvió aplicar con prioridad...las } \\
\text { otras condiciones del inciso a) del } \\
\text { articulo } 61^{\circ} \text { del Reglamento de la } \\
\text { Ley del Impuesto a la Renta, como } \\
\text { número de trabajadores, monto de } \\
\text { los pasivos, monto de compras, } \\
\text { costos y gastos, capital invertido en } \\
\text { la explotación, existencia de } \\
\text { mercaderías o bienes, entre otros". }\end{array}$ & $\begin{array}{l}\text { El } \\
\text { procedimiento } \\
\text { de } \\
\text { determinación } \\
\text { de la obligación } \\
\text { sobre base } \\
\text { presunta no se } \\
\text { encuentra } \\
\text { arreglo a } \\
\text { norma. }\end{array}$ & $\begin{array}{l}\text { No } \\
\text { cumple con } \\
\text { la exigencia }\end{array}$ \\
\hline
\end{tabular}

Nota. Elaboración propia.

Respecto de la primera exigencia, basta la configuración de uno de los supuestos del artículo $64^{\circ}$ del Código Tributario, la cual, de acuerdo a los hechos expuestos en la "Tabla 1", se encuentra debidamente acreditada la causal de presunción prevista en el numeral 2) del cuerpo tributario (la documentación sustentatoria o complementaria ofrece dudas respecto a su veracidad), por lo que, sobre esta exigencia, la entidad tributaria ha actuado conforme a norma sustantiva, respetando el principio de legalidad. Sin embargo, no se observa una actuación conforme a norma, respecto de la segunda exigencia, cuál es, la aplicación de un procedimiento de presunción expresamente contemplado en norma adjetiva.

Respecto al procedimiento de determinación de tributo sobre base presunta, el numeral 2) del artículo $91^{\circ}$ de la Ley del Impuesto a la Renta, aprobado por D.S. N ${ }^{\circ} 179-2004-E F$, establece que la SUNAT puede determinar la obligación tributaria, en base a 'Presunción de ventas, ingresos o renta neta por aplicación de promedios, coeficientes y/o porcentajes'. Para fijar el promedio, la SUNAT debe emplear, entre otros, el 
procedimiento de 'presunción de renta neta equivalente al promedio de renta neta de empresas similares' y que de estas se debe tomar en cuenta tres empresas con condiciones similares, de no haber empresas con dicho requisito, se tendrá en cuenta aquellas que tengan la misma Clasificación Industrial Internacional Uniforme - CIIU (numeral 3 del artículo $93^{\circ}$ del Código Tributario).

Por su parte, la norma adjetiva, "el artículo $61^{\circ}$ del reglamento de la Ley del Impuesto a la Renta, establece las condiciones que deben considerarse para determinar qué empresas pueden considerarse similares, así como los criterios para seleccionar a las mismas. De acuerdo a la Resolución $\mathrm{N}^{\circ}$ 074-003-0022523, la SUNAT determinó renta neta presunta en base a la 'presunción de renta neta equivalente al promedio de renta neta de empresas similares' en aplicación del numeral 3) - artículo $93^{\circ}$ de la Ley del Impuesto la Renta y el artículo $61^{\circ}$ de su reglamento; sin embargo, las tres empresas seleccionadas, si bien con las misma CIIU como exige el numeral 4) del artículo $61^{\circ}$ del reglamento de la Ley, eran contribuyentes con mayor impuesto resultante, y no similares, de acuerdo a sus ingresos facturados; además la entidad tributaria, no consideró las otras condiciones del inciso a) del artículo $61^{\circ}$ del Reglamento de la Ley del Impuesto a la Renta, como es el número de empleados, monto de los pasivos, monto de compras, costos y gastos, capital invertido, existencia de mercaderías, entre otros, vulnerándose de esa manera el principio de legalidad tributaria y constitucional, al no cumplir con la norma adjetiva. En ese mismo sentido se la manifestado el Tribunal Fiscal, en su Sentencia $\mathrm{N}^{\circ}$ 00035-10-2018. Es cierto que la Administración tributaria aplicó una de las condiciones establecidas en el artículo mencionado; sin embargo, no se respetó el orden de prioridad establecido, ocasionándose perjuicio patrimonial al contribuyente.

El procedimiento de determinación sobre base presunta resultaría ilegal si, en vez de restituir la situación de igualdad en el cumplimiento de obligaciones tributarias, generara por su aplicación una desigualdad, al exigirse al contribuyente que se encuentra inmerso en una causal habilitante de la presunción, obligaciones tributarias mayores a las que pudiera corresponderle a un contribuyente semejante respecto del cual se determina su obligación sobre base cierta (Córdova, 2008, citado por Vargas Ortega, s.f.).

En un Estado Constitucional de Derecho, no basta proclamarse los derechos fundamentales sino, y sobre todo, hacer efectivos esos derechos en los actos de contribución (Romero, Grass y García, 2013), lo que no sucede en la praxis de la Administración Tributaria, donde se demuestra que el uso de las presunciones sobre base presunta en materia tributaria en el Perú es "laxo" por no decir, "arbitrario". Es importante la aplicación rigurosa y ortodoxa de este instrumento que la ley tributaria otorga a la administración para determinar la imposición tributaria con la mayor exactitud. En el caso analizado, se advierte que la Administración tributaria no ha actuado con arreglo a ley en la Resolución de Determinación $N^{\circ}$ 00035-10-2018, es decir incumplió una las exigencias para determinar la obligación sobre base presunta. Ya lo habían advertido Chau y Lozano (2000: 29): "la determinación sobre base presunta puede significar, si es interpretada de manera incorrecta, un abuso de poder por parte de la Administración Tributaria”.

\section{CONCLUSIONES}

La jurisprudencia revisada en materia tributaria indica que la Administración Tributaria, pese a tener reglas establecidas para imponer impuesto a la renta por el método de determinación sobre base presunta, incumple el principio de legalidad. En el caso de la Resolución de Determinación N ${ }^{\circ}$ 074-003-0022523, la Administración al no haber cumplido con los establecido en el artículo $61^{\circ}$ del reglamento de la Ley del Impuesto a la Renta, ha vulnerado el principio de legalidad prescrita en el artículo $74^{\circ}$ de la Constitución Política del Perú, el mismo que se ratifica en los principios del Derecho administrativo, y la norma adjetiva en materia tributaria.

Siendo recurrente los excesos que la Administración Tributaria comete al aplicar la potestad de determinación tributaria, se entiende ello por negligencia del servidor de la entidad, es importante establecer una sanción administrativa para los responsables, incorporándose en el régimen disciplinario de la SUNAT 
una sanción, a fin de evitar daños materiales al contribuyente y abusos posteriores que implican una inversión insulsa de tiempo dinero y energías que pocas veces son resarcidos por la administración. El principio de legalidad es no negociable, por lo que no puede ser vulnerado por la administración tributaria porque afecta los derechos del contribuyente como el de propiedad, debido proceso e igualdad ante la ley. Si la potestad de determinación tributaria se aplica incorrectamente, el Estado decae en abuso de poder. Si bien es atribución de la Administración Tributaria recabar impuestos para que el Estado pueda cumplir con sus fines esenciales, esta no puede efectuar excesos y abusos de autoridad en detrimento patrimonial del contribuyente (persona o empresa). Es vital que los principios constitucionales y tributarios brinden seguridad y protección al contribuyente para así evitar arbitrariedades por parte de la administración tributaria.

\section{REFERENCIAS BIBLIOGRÁFICAS}

Alarcón Vargas, F. (2015). Estudio del procedimiento de determinación tributaria en base presunta establecido en el numeral 1 del articulo 93 de la Ley del Impuesto a la renta frente a la realidad económica y capacidad contributiva de las empresas como luchar contra la evasión tributaria en el sector grifos. https://cybertesis.unmsm.edu.pe/han dle/20.500.12672/4309

Baldeón Güere, N.; Roque Cabanillas, C. y Garayar Llimpe, E. (2009). Código Tributario comentado. Imprenta Editorial El Búho E.I.R.L.

Carrasco Talavera, A, y Arrieta Veliz, L. (2017). Hermenéutica dogmática jurídica del delito de nombramiento ilegal para cargo público y su relevancia constitucional. Universidad Peruana Los Andes. http://repositorio.upla.edu.p e/handle/UPLA/195

Chau Quispe, L. y Lozano Byrne, O. (2000). La Determinación sobre Base Presunta: Un Punto de Vista Jurisprudencial. THEMIS41. http://revistas.pucp.edu.pe/index.php/themis/article/view/11649/12188

El Peruano, Diario Oficial. Normas Legales. Constitución Política del Perú - 1993.

El Peruano, Diario Oficial. Normas Legales. Ley del Procedimiento Administrativo General. Ley No27444.

Eseverri, E. (1995). Presunciones legales y Derecho Tributario. Instituto de Estudios Fiscales, Marcial Pons.

Giuliani Fonrouge, C. M. (2004). Derecho Financiero señala. Talleres Gráficos de La Ley.

Gomez Bastar, S. (2012). Metodología de la investigación. Red Tercer Milenio. http://www.aliat.org.mx/BibliotecasD igitales/Axiologicas/Metodologia_de_la_investigacion.pdf

Henkel, H. (1968). Introducción A La Filosofía Del Derecho. Editorial B De F.

Hernández, R. (2017). Metodología de la Investigación. In P. Fernández, C., y Baptista (Ed.), The British Journal of Psychiatry (6ta. Edición, Vol. 112). https://doi.org/https://doi.org/10.1192/bjp.112.483.211-a

Jurista Editores. (2020). Código Civil. Jurista Editores E.I.R.L.

Oelckers Camus, O. (1977). El principio de legalidad como supuesto de la potestad administrativa. Revista de Derecho de la Universidad Católica de Valparaiso, 10 (1). http://www.rdpucv.cl/index.php/rderecho/article/viewArtic le/ 10

Romero-Molina, C. A., Grass-Suárez, Y. C. y García-Caicedo, X. C. (2013). Principios constitucionales que rigen el sistema tributario. Derecho y politicas públicas dixi, 15 (17). file://C:/Users/Pc/Downloads/DialnetPrincipiosConstitucionalesQueRigenElSistemaTributa-5572582.pdf

Sentencia del Tribunal Constitucional. EXP. No 01966-2005-PHC/TC MADRE DE DIOS CÉSAR AUGUSTO LOZANO ORMEÑO. https://www.tc.gob.pe/jurisprudencia/2005/01966-2005-HC.pdf

Sentencia del Tribunal Constitucional. EXP. N08495-2006-PA/TCLIMA RAMIRO EDUARDO DE V ALDIVIA. https://tc.gob.pe/jurisprudencia/2008/08495-2006-AA\%20Aclaracion.pdf

SUNAT. (2021). Texto Único Ordenado del Código Tributario. Decreto Supremo No 133-2013-EF. https://www.sun at.gob.pe/legislacion/renta/reglamento.html

SUNAT. (2021). Reglamento de la Ley de Impuesto a la Renta. Decreto Supremo Nº86-2020-EF. Disponible en ht tps://www.sunat.gob.pe/legislacion/renta/reglamento.html 
SUNAT. (2021). Ley del Impuesto a la Renta. Decreto Legislativo $N^{\circ}$ 1488. https://www.sunat.gob.pe/legislacion/r enta/tuo.html

Vargas Castillo, M. A. (2016). Los desaciertos en la aplicación de la base presunta en el caso costarricense: Un llamado de atención a la necesidad de apegarse al libreto de la ley y sus implicaciones técnico-jurídicas. Revista Instituto Colombiano de Derecho Tributario, núm. 75. http://www.icdt.co/publicaciones/revistas/Revista75/Articulo6/PUB_ICDT_ART_VARGASC.Modest oA._Losdesaciertosenlaaplicaciondelabasepresuntaenelcasocostarricense_RevistaICDT75_Bogota_16.pdf

Vargas Ortega, C. A. (s.f.). La Determinación de impuesto sobre base presunta y vulneración a la capacidad contributiva del contribuyente.

Villegas, H. (1999). Curso de Finanzas, Derecho Tributario y Financiero. Ediciones Depalma.

Villegas, H. (1994). Derecho Financiero y Tributario. De Palma. 